\title{
Application of fiber reinforced high performance composites in spun-cast elements
}

\author{
J. P. Kaufmann ${ }^{1}$, D. Hesselbarth ${ }^{1}$, K. Moser ${ }^{1}$ and G. P. Terrasi ${ }^{2}$ \\ (1) Empa, Swiss Federal Laboratories for Materials Testing and Research, Laboratories for Concrete \& Construction \\ Chemistry, Überlandstrasse 129, CH-8600 Dübendorf, Switzerland \\ (2) SACAC AG, Lenzburg, Switzerland
}

Received: 8 December 2004; accepted: 21 January 2005

\begin{abstract}
Spin casting is an effective method to produce concrete pylons, masts or pipes. Through the centrifugation process the concrete is compacted and the desired shape, mostly round or ellipsoidal, is obtained. The pre-cast elements made using conventional concrete generally have to be reinforced with steel bars which are susceptible to corrosion. Furthermore, the placement of the steel reinforcement is time consuming and hence expensive and leads to rather thick and heavy structural elements. The application of short fiber reinforced cement (FRC) or mortar, as presented in this paper, is a suitable altemative for such weak-loaded bending elements. Special requirements regarding workability and strength have to be considered. Optimization of cement matrix was achieved with a blend of microfine cement and ordinary Portland cement, improving the rheological properties of the fresh mixture and resulting in a very dense cement matrix with excellent mechanical properties. Reinforcement with different kinds of short fibers of carbon and polyvinylalcohol was studied. Flow properties of the FRC were optimized with regard to the centrifugation process applying a new cone-consistency test. The mechanical properties of conventionally cast specimens and of centrifuged prototypes were investigated.
\end{abstract}

1359-5997 (C) 2005 RILEM. All rights reserved.

\section{RÉSUMÉ}

La coulée centrifige est une méthode efficace pour produire des pylônes ou des inyaux en béton. La centrifugation provoque le compactage du béton et permet d'obtenir la forme désirée, le plus souvent circulaire ou ellipsoüdale. En règle générale le béton doit être renforcé au moyen d'aciers d'armature qui sont sensibles à la corrosion. De plus la pose de cette armature demande beaucoup de temps et est ainsi coûteuse et elle conduit encore à des éléments structuraux plutôt épais et lourds. L'utilisation de ciment ou de mortier renforcé de fibres courtes (CRF) représente une alternative intéressante pour les éléments soumis à de faibles charges de flexion. L'utilisation de ce matériau demande toutefois de tenir compte d'exigences particulières concernant son onvrabilité et sa résistance. Pour optimiser la matrice de ciment, on a utilisé un mélange de ciment ultrafin et de ciment Portland ordinaire, ce qui a pernis d'améliorer les propriétés rhéologiques du mortier frais et d'obtenir une matrice de ciment très dense présentant d'excellentes caractéristiques mécaniques. Les performances du renforcement au moyen de différents types de fibres de carbone et d'alcool polyvinylique ont été étudiées. Les propriétés d'écoulement du CRF ont été optimisées pour le processus de centrifugation en utilisant un nouvel essai d'étalement au cône. Une étude comparée des caractéristiques des éprouvettes coulées de manière conventionnelle et d'éprouvettes confectionnées par coulée centrifuge a été réalisée.

\section{INTRODUCTION}

Cementitious materials are known to be very brittle in bending and tension, with small strength and strain capacity. To overcome the brittle behavior of concrete a steel reinforcement is usually necessary in order to use concrete as a construction material. Pylons, masts, pipes, pillars and other building elements may be produced of steel bar reinforced concrete applying a spin-cast method $[1,2]$. The specially designed steel bar reinforcement is placed into a mould, the concrete is poured over it and then the mould is closed and rotated around its symmetry axis. The application of reinforcement of the concrete in such elements with steel bars is time intensive and expensive, susceptible to corrosion when the cover is too small and hence leads to relatively thick and heavy structural elements. The substitution of the steel bars by high performance short fibers may allow to produce thinner, lighter and cheaper elements. A much more efficient production would be possible [3]. The fiber reinforced cementitious (FRC) material should show very high strength in 
flexure and tension and must have rather specific workability to be formed by the resulting centrifugal forces and to acquire sufficient green body strength to prevent disintegration.

A prerequisite for the development of FRC is an appropriate, optimized cement matrix [4]. The matrix should combine properties such as low porosity, high density, and excellent mechanical properties. It can be obtained by combining two or more binder components with different size distributions [5]. The addition of microfine cement to the ordinary Portland cement improves the rheological properties of the fresh mixture and will lead to a dense cement matrix with high strength [6].

Short, high performance fibers are added to increase the flexural and tensile strength as well as the ductility of the cement matrix. From the processing point of view, the workability of the fresh cement mix containing fibers is very important. Fibers tend to stiffen the mix. The problem of obtaining good fiber dispersion and consistency becomes more demanding for very low water/binder ratios $(w / b<0.25)$.

For the centrifugation process, the fiber cement mixture is required to be thixotropic, which means that it should flow during the spinning process and get stiff after the centrifugation. The fibers should move well during the centrifugation, in order to reach a homogeneous distribution in the matrix. Care has to be taken that no segregation of any mixture component occurs during centrifugation. For this reason and because of their corrosion tendency, metallic fibers are not suitable to be applied owing to their high density. Carbon and high performance polyvinylalcohol (PVA) fibers were used instead [7-9]. properties are given in Table 1. The fibers were added to the fresh pastes and mixed another 2 minutes in the same mixer. The rheological properties of the fresh fiber composite was analyzed applying a cone-consistency test where a conical measuring bob is moved at a constant velocity of $0.5 \mathrm{~mm} / \mathrm{s}$ into a hollow cone filled with the fresh mixture. The resulting force is recorded as function of the displacement [11].

The production of the spun-cast elements was done under real conditions on a fabrication line of SACAC AG, Lenzburg Switzerland. The mix design of centrifuged pipes (diameter $200 \mathrm{~mm}$, wall thickness $25 \mathrm{~mm}$, total length $2 \mathrm{~m}$ ) and the rotation speed are given in Table 2 . The composites were mixed using a conventional concrete mixer. The pipes remained in the mould for 1 day and were then stored under water.

Additionally, spun-cast lighting pylons (conical, diameter top end $90 \mathrm{~mm}$, diameter bottom end $163 \mathrm{~mm}$, length $4.2 \mathrm{~m}$ ) were fabricated. The mix design is given in Table 3. The rotation speed at the spindle was set to $741-784 \mathrm{rpm}$, which

\begin{tabular}{|l|c|c|}
\hline \multicolumn{3}{|c|}{ Table 1 - Fiber properties } \\
\hline & $\begin{array}{c}\text { Carbon } \\
\left(\text { PAN }^{*}\right)\end{array}$ & PVA \\
\hline E-Modulus / GPa & 228 & 40 \\
\hline Strength (tension) / GPa & 3.8 & 1.6 \\
\hline Elongation at rupture / \% & 1.5 & 6.0 \\
\hline Density / g/cn ${ }^{3}$ & 1.81 & 1.30 \\
\hline Diameter / $\mu \mathrm{m}$ & 7.2 & 40 \\
\hline Length / $\mathrm{mm}$ & 6.35 & $6 / 12$ \\
\hline
\end{tabular}

"based on polyacrylonitril

\section{MATERIALS AND METHODS}

In order to improve the mechanical and rheological properties of the cementitious matrix, a blend of microfine cement based on blast furnace slag with ordinary Portland cement CEM I $42.5 \mathrm{~N}$ was used [10]. Conventionally cast prisms $\left(25 \times 25 \times 100 \mathrm{~mm}^{3}\right)$ and spin-cast elements were produced. The pastes for the prisms and the characterization of the rheological properties were prepared using an EN 196-1 type moltar mixer. A polycarboxylate type superplasticizer (solid mass content $32 \%$ ) was added. The time of mixing was $3 \mathrm{~min}$ at $62.5 \mathrm{rpm}$ according to EN 196-3. Two different fiber types (carbon and PVA) were used as mechanical reinforcement of the cement paste. Their

\begin{tabular}{|c|c|c|c|c|c|c|c|c|}
\hline \multicolumn{9}{|c|}{ Table 2 - Mix design and centrifugation parameters for the centrifuged pipes } \\
\hline batch & $\begin{array}{l}\text { CEM I } \\
42.5 \mathrm{~N} \\
\text { mass- } \%\end{array}$ & $\begin{array}{l}\text { microfine } \\
\text { cement }\end{array}$ & $\begin{array}{l}\mathrm{w} / \mathrm{b} \\
\text { (water/ } \\
\text { binder) }\end{array}$ & $\begin{array}{l}\text { Super- } \\
\text { plasticizer } \\
\text { mass-\% } \\
\text { /binder }\end{array}$ & $\begin{array}{c}\text { PVA } \\
\text { fiber } \\
\text { (6nm } \\
\text { length) } \\
\text { vol.- } \%\end{array}$ & $\begin{array}{l}\text { Carbon } \\
\text { fiber }\end{array}$ & $\begin{array}{c}\text { Rotation } \\
\text { speed } \\
\text { spindle } \\
\text { rpm }\end{array}$ & $\begin{array}{c}\text { acceleration } \\
a_{c} \\
\text { outer/inner } \\
g\end{array}$ \\
\hline M1 & 75 & 25 & 0.155 & 2.5 & 4.5 & 0 & 903 & $37 / 27$ \\
\hline M2 & 75 & 25 & 0.17 & 2.5 & 4.5 & 0 & 918 & $38 / 28$ \\
\hline M3 & 75 & 25 & 0.17 & 2.5 & 4.5 & 0.5 & 860 & $33 / 25$ \\
\hline M4 & 75 & 25 & 0.155 & 2.5 & $4.5^{* 67}$ & 0 & 741 & $24 / 19$ \\
\hline M5 & 75 & 25 & 0.155 & 2.5 & $4.5^{* * *}$ & 0 & 741 & $24 / 19$ \\
\hline M6 & 75 & 25 & 0.16 & 2.5 & 4.5 & 0.5 & 870 & $34 / 26$ \\
\hline M7 & 75 & 25 & 0.155 & 2.5 & 4.5 & 0 & 850 & $33 / 25$ \\
\hline $\left.\mathrm{M} 8^{*}\right)$ & 75 & 25 & 0.151 & 2.5 & 4.5 & 0 & 741 & $27 / 21$ \\
\hline $\mathrm{M}^{* *}$ & 75 & 25 & 0.16 & 2.5 & 1.5 & 0 & 741 & $24 / 19$ \\
\hline
\end{tabular}

${ }_{* *}^{*)}$ polycarboxylate type II

**) sand 0-3 mm, relation 1: I to binder.

${ }^{* * *}$ fiber length $12 \mathrm{~mm}$

\begin{tabular}{|l|c|c|c|c|c|c|c|}
\hline \multicolumn{6}{|c|}{ Table 3 - Mix design and process parameters for the production of spun lighting pylons } \\
\hline Batch & $\begin{array}{l}\text { CEM I } \\
42.5 \mathrm{~N} \\
\text { mass- \% }\end{array}$ & $\begin{array}{l}\text { Microfine } \\
\text { cement } \\
\text { mass- \% }\end{array}$ & w/b & superplastizicer & PVA fiber & $\begin{array}{l}\text { carbon } \\
\text { fiber } \\
\text { vol.-\% } \%\end{array}$ & $\begin{array}{l}\text { rotation } \\
\text { speed } \\
\text { rpm }\end{array}$ \\
\hline P1 & 75 & 25 & 0.16 & 2.5 & $4.5(6 \mathrm{~mm})$ & 0.5 & 784 \\
\hline P2 & 75 & 25 & 0.155 & 2.5 & $4.5(6 \mathrm{~mm})$ & 0 & 741 \\
\hline P3 & 75 & 25 & 0.15 & 2.5 & $4.5(6 \mathrm{~mm})$ & 0 & 741 \\
\hline P4 & 75 & 25 & 0.155 & 2.5 & $3.5(6 \mathrm{~mm})$ & 0 & 741 \\
\hline P5 & 75 & 25 & 0.15 & 2 & $4.5(6 \mathrm{~mm})$ & 0 & 741 \\
\hline P6 & 75 & 25 & 0.155 & 2 & $4.5(6 \mathrm{~mm})$ & 0 & 741 \\
\hline
\end{tabular}




\begin{tabular}{|c|c|c|c|}
\hline \multicolumn{4}{|c|}{ Table 4 - Acceleration level in prototype production } \\
of lighting pylons \\
\hline $\begin{array}{c}\text { rotation } \\
\text { speed of } \\
\text { spindle }\end{array}$ & $\begin{array}{c}\text { rotation } \\
\text { speed of } \\
\text { running } \\
\text { wheel } \\
\text { rpm }\end{array}$ & $\begin{array}{c}\text { acceleration } \\
a_{c, \text { bottom }} \\
\text { outside/inside }\end{array}$ & $\begin{array}{c}\text { acceleration } \\
\mathrm{a}_{\mathrm{c}, \text { top }} \\
\text { outside/inside }\end{array}$ \\
\hline 784 & 504 & $\mathrm{~g}$ & $\mathrm{~g}$ \\
\hline 741 & 476 & $23 / 17$ & $13 / 7$ \\
\hline
\end{tabular}

" calculated with wall thickness $20 \mathrm{~mm}$

is the maximal (security reasons) achievable value. The centrifugation conditions and acceleration levels are summarized in Table 4. Due to the small diameter small centrifugal acceleration values for the top end of the lighting pylons are calculated. The acceleration level at the bottom end is much higher reaching the values for the spun-cast pipes. In some cases, an early setting (not observed in laboratory conditions), probably induced by a higher energy input of the mixer was observed.

Some loss of mechanical strength and homogeneity might have resulted. After production the lighting pylons remained in the mould for 1 day and were then covered by wet towels and a plastic foil to prevent from desiccation.

The three-point bending strength was determined on conventionally cast prisms $\left(25 \times 25 \times 100 \mathrm{~mm}^{3}\right.$, span $80 \mathrm{~mm}, 6$ specimens). The specimens were cured under water prior to testing.

In addition, prisms $\left(15 \times 15 \times 80 \mathrm{~mm}^{3}, \quad 15\right.$ specimens) were cut from spun-cast elements after $7 \mathrm{~d}$ water curing. After cutting the specimens were stored at $20^{\circ} \mathrm{C} / 70 \% \mathrm{RH}$ and finally tested at an age of $28 \mathrm{~d}$ (3-point, span $45 \mathrm{~mm}$ ).

In the bending test, the displacement was measured by a displacement gauge at the bottom of the prisms.

Bending strength also was tested on spun-cast pipe sections (diameter $200 \mathrm{~mm}$, length $650 \mathrm{~mm}$ ) in a threepoint testing arrangement (see Fig. 1, span $600 \mathrm{~mm}$ ). The displacement was measured on the bottom of the pipe.

The bending strength was calculated as follows:

$$
\sigma=\frac{s \cdot F \cdot R}{\left(R^{4}-r^{4}\right) \pi}
$$

$$
\begin{aligned}
\text { where } & s: \\
F & : \text { span }[\mathrm{mm}] \\
R & : \text { outer radius }[\mathrm{mm}] \\
\mathrm{r} & : \text { inner radius }[\mathrm{mm}]
\end{aligned}
$$

The spun-cast lighting pylons were tested horizontally in a cantilever beam test arrangement as shown in Figs. 2 and 3. The pylons were fixed at their bottom end. The force was applied horizontally at the top end. Bending due to deadweight was counteracted by a support (crane). The deformation of the pylon was measured at different positions. In this paper only some results for the bending of the top end are presented. Testing was performed at an age of 28 days. The pylons remained wrapped into the moist towels and the plastic foil until this moment.

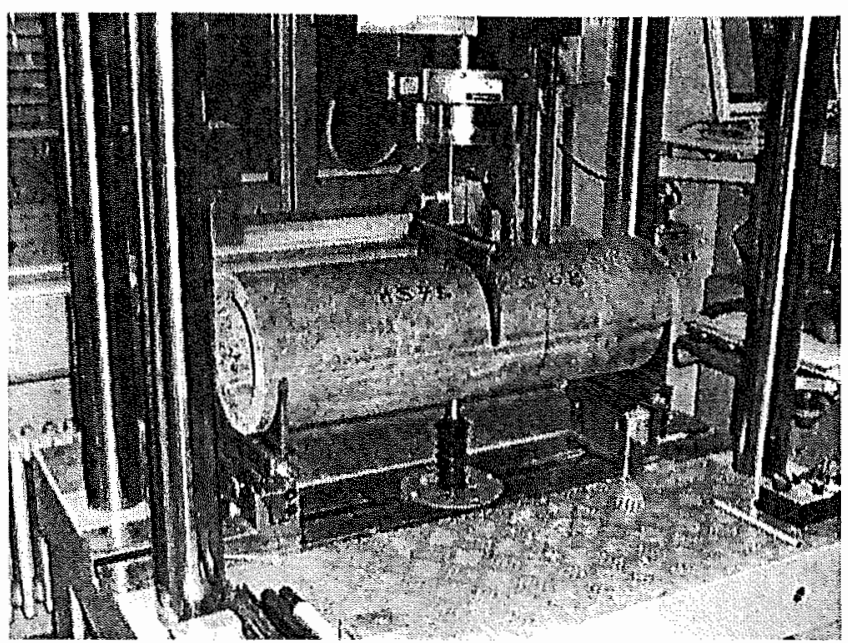

Fig. 1 - Arrangement of 3-point bending test of pipe sections.

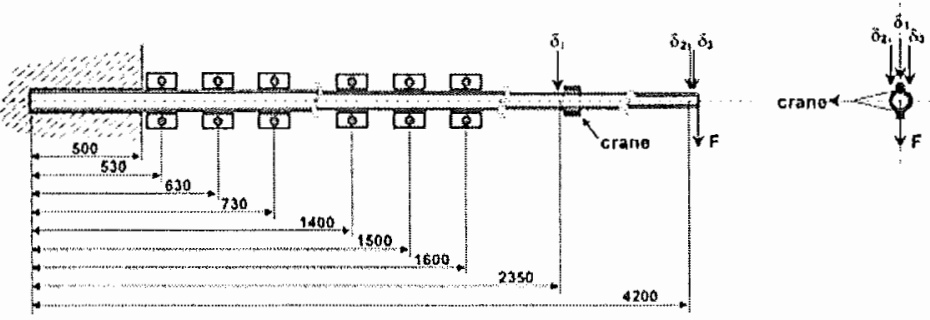

Fig. 2 - Test arrangement for cantilever beam test.

The bending strength was calculated as follows:

$$
\sigma=\frac{F_{u} \cdot l_{\text {crack }} \cdot R}{\left(R^{4}-r^{4}\right) \frac{\pi}{4}}
$$

where $\quad F_{u}$ : ultimate force $[\mathrm{kN}]$

$l_{\text {crack }}:$ crack position from load [mm]

$\mathrm{R}$ : outer radius at crack position [mm]

$\mathrm{r}$ : inner radius at crack position [mm]

\section{RESULTS}

In order to increase the mechanical properties of a cementitious composite, the addition of carbon fibers may be favored due to their outstanding mechanical performance. But this fiber type bears significant disadvantages regarding the rheology of the fresh mixes. The small diameter of carbon fibers leads to a significant decrease in the workability. An example is plotted in Fig. 4.

The fineness of the fibers influences the workability significantly the addition of only 0.5 vol.- $\%$ of carbon fibers decreases the consistency of a carbon-PVA hybrid drastically. On the other hand, a further addition of the coarse PVA fibers (not shown in the figures) had only a minor effect on the rheological properties. The production of coarser high strength carbon fiber (PAN-based) is economically uninteresting. However somewhat coarser 


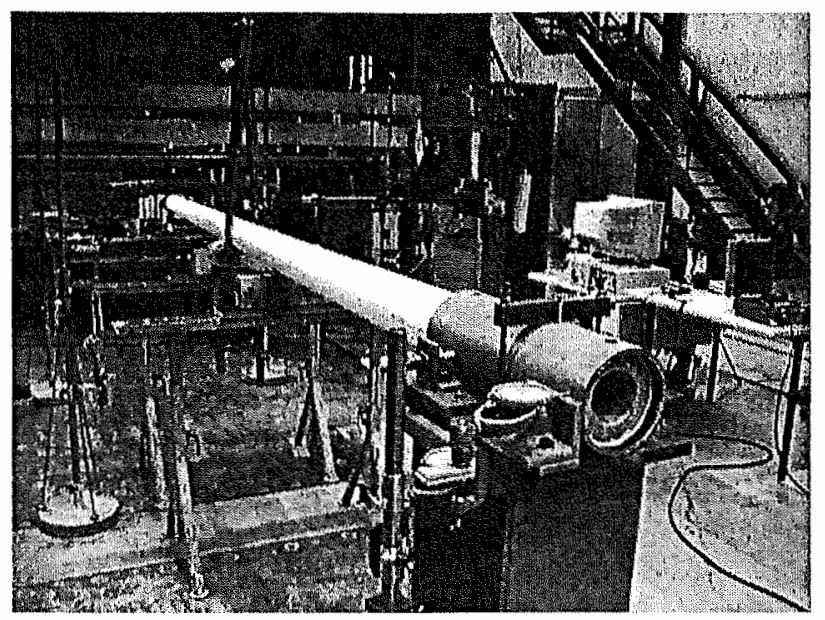

Fig. 3 - Clamped lighting pylon in cantilever beam test.

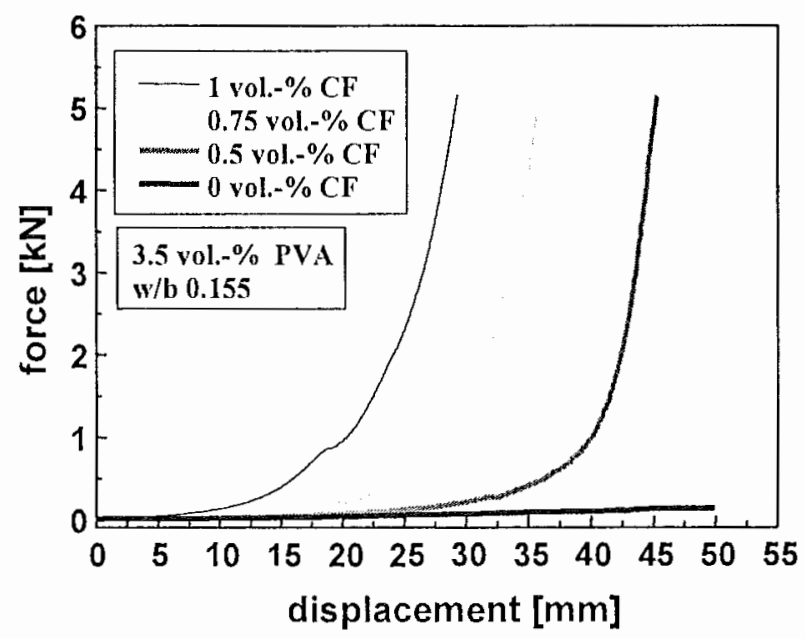

Fig. 4 - Effect of the addition of carbon fibers on the workability of a composite containing 3.5 vol.-\% PVA fibers (cone-consistency).

pitch-based carbon fibers are commercially available but they have lower mechanical properties.

The workability of pure carbon fiber reinforced composites with a fiber content of more than 1.5 vol.- $\%$ was too poor to be used in a spun-casting process.

At the same time it is necessary that the fiber content exceeds this amount to fulfill the strength requirements. Hence for prototype production, carbon fibers were added in dosages of less than $0.5 \mathrm{vol} .-\%$ and mostly PVA fiber reinforced composites with much improved workability properties were studied further (see mix designs Tables 2 and 3).

Another advantage of PVA fiber reinforced composites is their ductile fracture whereas the rupture of high strength carbon fiber composites is rather brittle. When using a matrix consisting of a blend of portland cement with microfine cement and adding PVA fibers, very high strength and ductile composites result. The average bending strength of conventionally cast prisms (M1 Table 2) reaches $32.1 \mathrm{MPa}$ at an age of 7 days and $30.5 \mathrm{MPa}$ at 28 days. The force displacement curves of nine individual conventionally cast specimens are plotted in Fig. 5.

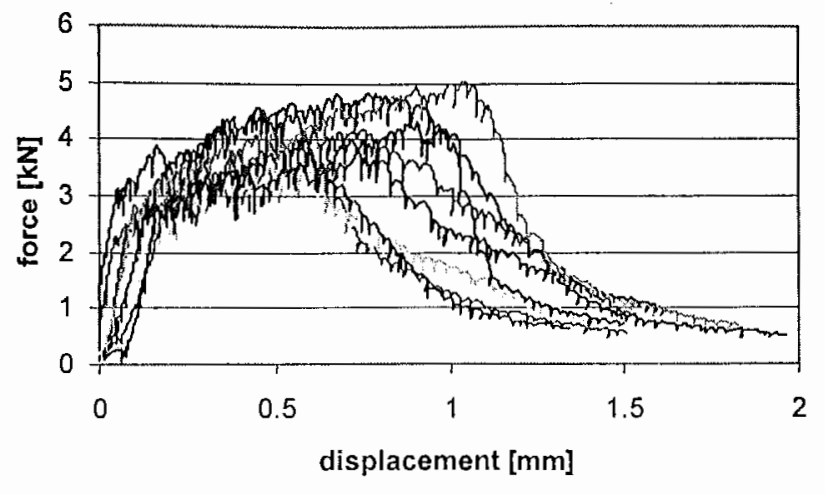

Fig. 5 - Force-displacement curves of specimen in 3-point bending test (mix 1 Table 2 , conventionally cast prisms $25 \times 25 \times 100 \mathrm{~mm}^{3}, 28 \mathrm{~d}$, PVA fibers).

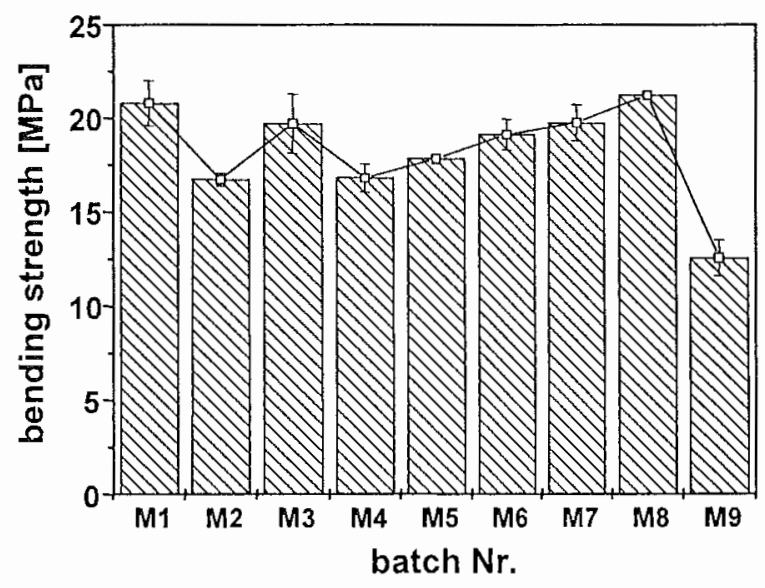

Fig. 6 - Bending strength (3-point bending) of pipes fabricated with the centrifugation technique.

The bending strengths of spun-cast pipes (mixed composites according Table 2) at an age of 28 days as obtained in a three point test arrangement (Fig. 1) are plotted in Fig. 6. The average bending strengths of the pipes are found to be considerably lower than the ones obtained for conventionally cast prisms. This may be partially due to the size effect, but also because of material inhomogeneities introduced by insufficient compaction or phase segregation in the inhomogeneous acceleration field during centrifugation. The scattering is generally relatively small (3-pipe section for each mix design), but somewhat increased compared to pure PVA fiber composites when carbon fibers are added (M3, M6). The addition of carbon fibers reduces the workability but increases the first crack strength slightly. The application of an alternative polycarboxylate type superplasticizer (M7) influences the fluidity positively, reduces the water demand of the mix and leads to more homogeneous elements and higher bending strength. Longer fibers have a negative influence on the workability and for this reason on the bending strength (M1 versus M4/5). The mixes M4 and M5 confirm a good repeatability of the results. The addition of $50 \%$ quartz-sand (grading $0.1-0.3 \mathrm{~mm}$ ) reduces the bending strength significantly. However this might be interesting alternative from economic considerations. 


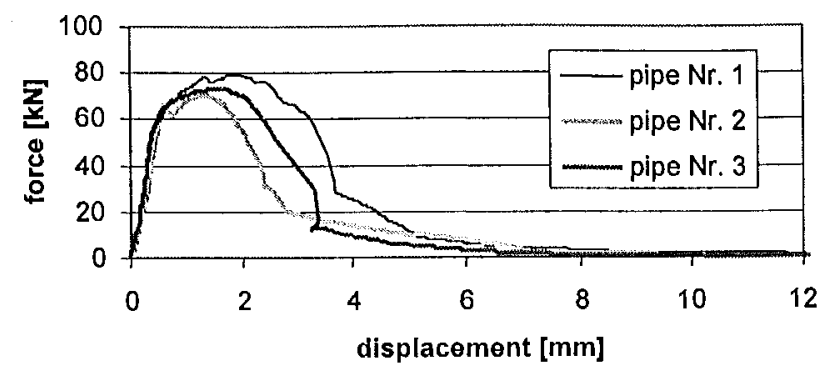

Fig. 7 - Force-displacement curves (3-point bending) for pipes fabricated with the centrifugation technique (mix Ml).

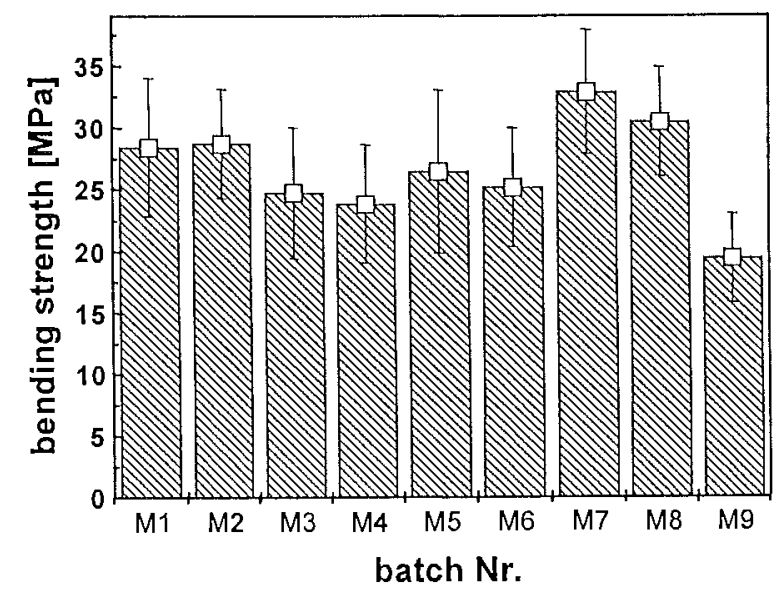

Fig. 8 - Strength of prisms (cut of pipes fabricated with centrifugation technique, $15 \times 15 \times 80 \mathrm{~mm}^{3}, 3$-point bending, span $45 \mathrm{~mm})$.

The force displacement plot (Fig. 7) shows a rather ductile failure behavior in the three point bending test. This is very important in elements like lighting pylons where a brittle failure could endanger people.

The bending strength of cut prisins $\left(15 \times 15 \times 80 \mathrm{~mm}^{3}\right)$ from spun-cast pipes is given in Fig. 8. Similar values as for conventionally cast prisms are measured. Scattering is relatively big and does not allow an in-depth discussion. However, qualitatively the results are similar as obtained in the three-point bending of pipe sections.

As an example for real construction elements spun-cast lighting pylons were fabricated. The mix designs are given in Table 3 and the centrifugation parameters in Table 4. A wall thickness of $25 \mathrm{~mm}$ should be reached during fabrication. Owing to the conicity of the lighting poles (diameter variation of $17.3 \mathrm{~mm} / \mathrm{m}$ ), the resulting centrifugal acceleration was not

\begin{tabular}{|l|l|c|c|c|c|c|}
\hline \multicolumn{2}{|c|}{ Table 5 - Dimensions of the spun-cast lighting pylons } \\
\hline & bottom end & P2 & P3 & P4 & P5 & P6 \\
\hline \multirow{2}{*}{$\begin{array}{l}\text { Diameter } \\
\text { (outside) } \\
{[\mathrm{mm}]}\end{array}$} & $3 \mathrm{~m}$ from bottom & 110 & 110 & 110 & 109 & 109 \\
\cline { 2 - 7 } & top end & 90 & 90 & 90 & 90 & 90 \\
\hline $\begin{array}{l}\text { Wall } \\
\text { thickness max } \\
{[\mathrm{mm}]}\end{array}$ & bottom end & 32 & 32 & 33 & 38 & 35 \\
\cline { 2 - 7 } & $3 \mathrm{~m}$ from bottom & 30 & 20 & 18 & 22 & 23 \\
\cline { 2 - 7 } & Top end & 25 & 25 & 15 & 18 & 25 \\
\hline $\begin{array}{l}\text { Wall } \\
\text { thickness min } \\
{[\mathrm{mm}]}\end{array}$ & botton end & 30 & 30 & 32 & 34 & 33 \\
\cline { 2 - 7 } & $3 \mathrm{~m}$ from bottom & 15 & 15 & 14 & 18 & 18 \\
\cline { 2 - 7 } & Top end & 18 & 18 & 10 & 15 & 17 \\
\hline
\end{tabular}

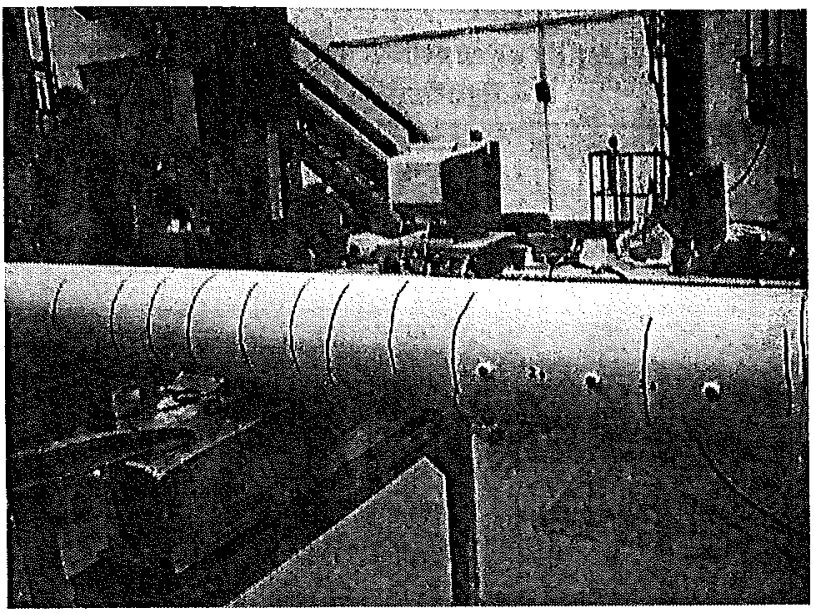

Fig. 9 - Multiple cracking in cantilever beam test (pylon P5).

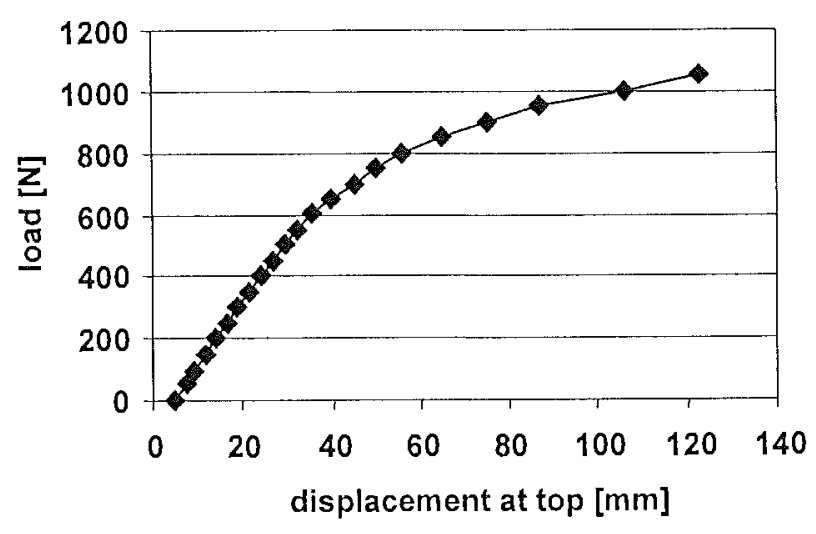

Fig. 10 - Displacement at top end of pylons vs. load (pylon P5).

constant across the length and a force gradient results. This lead to a lateral displacement of the composite and a nonconstant wall thickness. The measured wall thicknesses of the spun-cast pylons are given in Table 5 .

The wall thickness at the top end is significantly smaller than at the bottom end. One major problem is designing the fiber reinforced cementitious mix such that the fluidity is sufficient to form a homogeneous and well compacted wall, but on the other hand the mixture should not be too fluid to prevent from lateral displacement of the fresh composite towards the bottom end of the conical lighting pylons.

The spun-cast pylons were tested in a cantilever beam test as described above. The test results are given in Table 6. A rather ductile fracture behavior with multiple cracking (Fig. 9) was observed leading to a big displacement at the top end of the pylon (Fig. 10).

The ultimate crack was generally observed to be in a region between 1 and 2 meters from the clamped bottom end of the lighting pylons. At this region also very inhomogeneous wall thicknesses were observed. The calculated stresses at failure however were much lower than the tested performance in three point bending test (Table 6), but fulfill the requirements of the relevant standards [12].

The bending strength also was determined from cut prisms $\left(15 \times 15 \times 80 \mathrm{~mm}^{3}\right)$. The results are given in Table 7. Compared with the ones obtained from 


\begin{tabular}{|c|c|c|c|c|}
\hline Batch & $\begin{array}{c}\text { Position of } \\
\text { crack } l_{\text {crack }} \\
\text { Mm }\end{array}$ & $\begin{array}{c}\text { Force } \\
\mathrm{F}_{\text {crack }} \\
\mathrm{kN}\end{array}$ & $\begin{array}{l}\text { Stress } \\
\sigma_{\text {crack }} \\
\text { Mpa }\end{array}$ & $\begin{array}{l}\text { Displacement } \\
\text { at top end } \\
\mathrm{Mm}\end{array}$ \\
\hline P1 & 2100 & 0.705 & 8.3 & 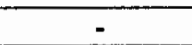 \\
\hline $\mathrm{P} 2$ & 1910 & 0.791 & 10.6 & 97.15 \\
\hline $\mathrm{P3}$ & 3060 & 0.937 & 13.6 & - \\
\hline $\mathrm{P} 4$ & 2400 & 0.65 & 9.9 & 96.31 \\
\hline P5 & 3050 & 1.104 & 14.5 & 122.91 \\
\hline P6 & 3370 & 0.95 & 12.4 & 100.78 \\
\hline
\end{tabular}

Table 7 - Bending strength and standard deviation of prisms cut from spun-cast lighting pylons

\begin{tabular}{|l|c|c|}
\hline Batch & $\begin{array}{c}\text { Bottom end } \\
\mathrm{MPa}\end{array}$ & $\begin{array}{c}\text { top end } \\
\mathrm{MPa}\end{array}$ \\
\hline P2 & $29.3 \pm 5.8$ & $20.2 \pm 5.8$ \\
\hline P3 & $28.3 \pm 3.7$ & $24.8 \pm 11.1$ \\
\hline P4 & $23.4 \pm 2.5$ & $21.4 \pm 5.5$ \\
\hline P5 & $27.4 \pm 4.9$ & $27.0 \pm 7.7$ \\
\hline P6 & $28.6 \pm 7.0$ & $28.6 \pm 6.9$ \\
\hline
\end{tabular}

cut prisms of spun-cast pipes or conventionally cast prisms, the absolute values at the bottom end of the pylons are of the same order of magnitude, but the scatter is much higher. The bending strengths at the top end of the pylons are lower with very high scatter. This may be explained by the much lower centrifugal accelerations during the production of the lighting pylons, especially at the top end, in comparison to those for the pipes of $200 \mathrm{~mm}$ diameter.

The lower performance in the cantilever beam test can be explained when looking at the cross sections of the spun-cast pylons. As an example, the sections near the top end, the bottom end and the centre of pylon P2, P5 and pipe Mi are shown in Fig. 11. The pylon that performed best in the cantilever beam test (P5) and pipe M1 shows much less inhomogeneities than pylon P2. Furthermore, some bright zones especially at the inside of the pylon are visible. These may be the result of an insufficient curing and compaction. Moist curing was applied only on the outside using wet towels. The pipes show much less insufficiently cured regions as curing in this case was done by full water immersion. Curing certainly is a very important factor for such high performance materials [13].

A further microscopical analysis revealed interesting details concerning the fiber distribution in spun-cast fiber rein-forced composites. An orientation along the rotation axis is observed (Fig. 12). This orientation will tend to increase the efficiency factor of the fibers in tension and bending of the composite [14].

\section{CONCLUSIONS}

In order to replace the heavy and costly conventional steel bar reinforced concrete in spun cast weak-bending-loaded elements, a new short fiber reinforced cementitious composite was developed. High strength requirements of the composition lead to the use of high performance fibers with high modulus

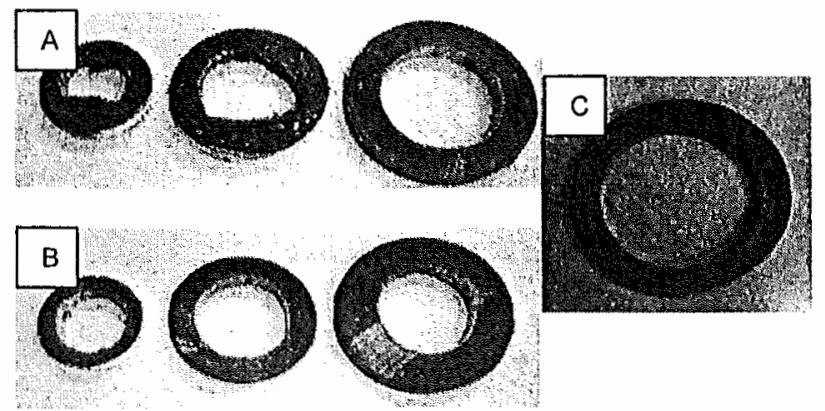

Fig. 11 - Cross section of spun-cast pylons P2 (A), P5 (B) and pipe Ml (C).

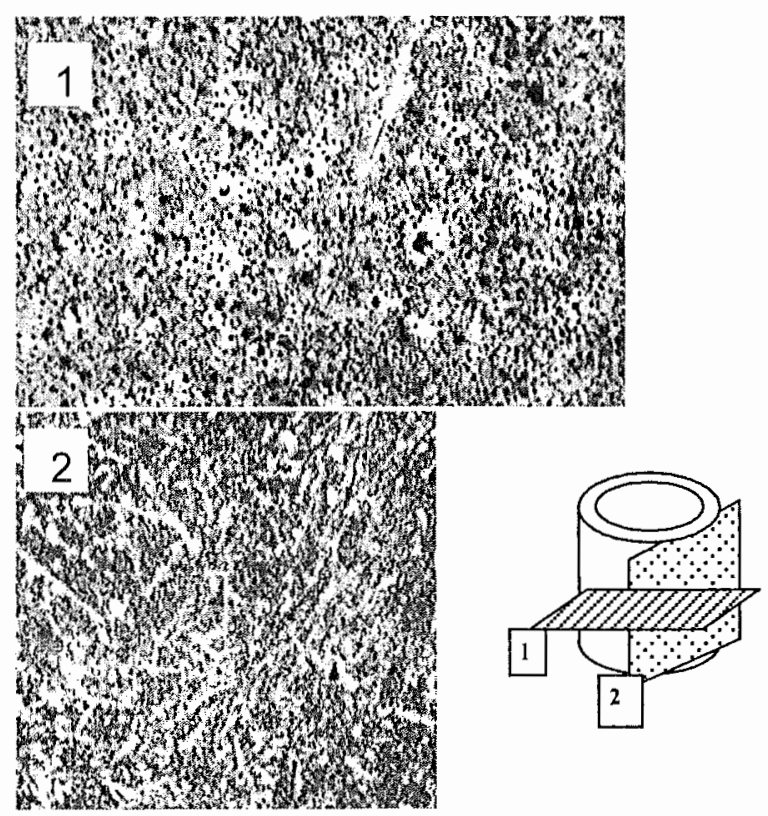

Fig. 12 - Fiber orientation in spun-cast pylon: In section 1 the fibers are observed as points, whereas in section 2 , the fibers are visible as long (bright) lines.

and strength. Owing to the high centrifugal accelerations which would lead to a segregation of steel fibers in spincasting process and to reduce the corrosion risk of steel, light polymer and carbon fibers were used instead.

Flow properties of the FRC were optimized for the centrifugation process using a new cone-consistency test. Best results regarding flow properties and strength were obtained for a mixture containing a blend of ordinary Portland cement and microfine cement based on blast furnace slag. The mechanical properties of conventionally cast specimens and of centrifuged prototypes were investigated. High strength and very high ductility were achieved for both conventionally cast specimen and centrifuged prototypes.

It was possible to produce spun-cast lighting pylons based on these mixtures which fulfill the normative requirements. However, further optimization of the spinning process and the mix design is required to produce viable spun-cast elements. 


\section{ACKNOWLEDGEMENTS}

This paper presents some results of a three-year research project on the application of fiber reinforced high performance composites in spin-casting fabrication. The project was supported by the Swiss Commission for Technology and Innovation (KTI/CTI) and SACAC AG (Lenzburg, Switzerland).

\section{REFERENCES}

[1] Terrasi, G.P., 'Carbon fiber reinforced pre-stressed spun-cast pipes', Thesis ETH Zürich, Nr. 12454, Zürich, 1998 [in German].

[2] Dilger, W.H. and Rao, S.V.K.M., 'High performance concrete mixtures for spun cast concrete poles', PCI Journal 42 (4) (1997) 82-96.

[3] Burnett, E.F.P, Constable, T. and Cover, P., 'Centrifugated wire fibre reinforced concrete' SP 44-26 (1974) 455-477.

[4] Katz, A. and Bentur, A., 'High performance fibres in high strength cementitious matrices', in 'High performance fibre reinforced cement composites' (RILEM, Publ. E \& FN Spon, 1992) $237-247$

[5] German, R., 'Particle Packing Characteristics, Metal powder industries federation' (Princeton, 1989).
[6] Kaufmann, J. and Winnefeld, F., 'Influence of addition of ultrafine cement on the rheological properties and strength of Portland cement paste', Proc. Int. Conf. Innovations and Developments in Concrete Materials and Construction, Dundee, UK, 2002, 827-836.

[7] Waller, A., 'Carbon fibre cement composites, Civil engineering and publics work review 67 (1972) 357-361.

[8] Ali, M.A., Majumdar, A.J. and Rayment, D.L., 'Carbon fibre reinforcement of cement', Cem. Concrete Res. 2 (1972) 201212.

[9] Zhijiang, Z. and Tian, C.Y., 'High tenacity PVA fibres: a suitable alternative for asbestos', Proc. Intern. Man-Made Fibres Congress, Austrian Chemical Institute, Sept. 1986.

[10] Kaufmann, J., Matschei, Th. and Hesselbarth, D., 'Effect of the addition of ultrafine cement on the properties of fibre reinforced composites', Proc. $11^{\text {th }}$ Int. Conference on the Chemistry of Cement ICCC Conference, Durban, South Africa (2003) 1683-1691.

[11] Kaufmann, J., Winnefeld, F., Hesselbarth, D. and Trindler, W., 'A new method for the evaluation of the consistency of fibre reinforced cementitious composites', paper submitted to Mater. Struct. (2004).

[12] European standard EN 40 1-4 (2000).

[13] Yurtdas, I., Burlion, N. and Skoczylas, F., 'Experimental characterisation of the drying effect on uniaxial mechanical behaviour of mortar', Mater. Struct. 37 (267) (2004) 170-176.

[14] Bentur, A. and Mindess, S., 'Fibre Reinforced Cementitious Composites' (Elsevier Barking, 1990). 
. 